DOI: $10.20472 /$ IAC.2018.038.013

\author{
HELENA FIALOVÁ \\ Czech Technical University in Prague, Czech Republic \\ LENKA ADAMCOVÁ \\ Metropolitan University Prague, Czech Republic \\ ALENA AMBROŽOVÁ \\ Czech Technical University in Prague, Czech Republic
}

\title{
NON-MARKET SERVICES AS QUATERNARY SECTOR OF THE ECONOMY
}

\begin{abstract}
:
Modern economic theories develop the original three-sectors economy into four- or even five sectors economy when creating the quarternary (or even quinary) sector of the economy. The quarternary sector should play the role of 'an engine' pushing and pulling the economic growth of the respective country up. Industries included in the quaternary sector consists of intellectual activities often associated with technological innovations (called the knowledge economy) based on high degree of education of labor. Some economists go on and create the quinary sector separating activities of top executives and officials in fields as government, science, universities and culture and also activities covering childcare and education.

This paper demonstrates another way of splitting the broad tertiary sector. It divides industries included in the tertiary sector into two groups: market and non-market services according to the definition of NACE or ISIC (statistical classifications used in EU or UN). The tertiary sector in the paper covers only market services. Non-market services on the other hand are represented by the quartenary sector and they comprise 4 NACE-CLIO branches. The basic idea for dividing the tertiary sector into two groups mentioned above was the similarity of market services with business activities included in the primary and secondary sectors. To some degree market services are closely connected with the performance of businesses in the primary and secondary sectors. Non-market services on the other hand, which are services provided usually free of charge or for a symbolic payment, include a special field of activities, which countries only on high economic levels "can afford" to grant and only with inceasing economic level may enlarge and develop.

The paper proves the conclusion of classical economists about changing shares of three production sectors with economic growth of a country in favor of the tertiary sector. The paper proved also a new hypothesis, namely that increasing economic level of a country is strongly linked to the growing share of non-market services, while the link to the share of market services is not so obvious.

The analysis includes statistical series of data of main member countries of European Union. The mathematical background and applied analytical functions are described, as well. A specialised software IBM SPSS has been used for correlation and regression analyses. All results are presented in the form of tables and graphs.
\end{abstract}

\section{Keywords:}

National income analysis, three-sector analysis, share of labor force in GDP, tertiary sector, quartenary sector, market services, non-market services. 
JEL Classification: A10 